\title{
Hydrogen positions and thermal expansion in lizardite-1T from Elba: A low-temperature study using Rietveld refinement of neutron diffraction data
}

\author{
M. Gregorkiewitz, ${ }^{1}$ B. Lebech, ${ }^{2}$ M. Meluini, ${ }^{1}$ ANd C. Viti ${ }^{1}$ \\ 'Dipartimento di Scienze della Terra, Università di Siena, via delle Cerchia, 3, I-53100 Siena, Italy \\ ${ }^{2}$ Department of Solid State Physics, Risø National Laboratory, DK-4000 Roskilde, Denmark
}

\begin{abstract}
The structure of lizardite- $1 T$ from Monte Fico, Elba, was refined in space group $P 31 \mathrm{~m}$ using neutron diffraction data, measured at 8,150 , and $294 \mathrm{~K}$, and full-profile Rietveld refinement techniques. The lattice parameters at $8 \mathrm{~K}[a=5.3267(2), c=7.2539(6) \AA]$, $150 \mathrm{~K}[a=5.3260(2), c=7.2574(6) \AA]$, and $294 \mathrm{~K}[a=5.3332(2), c=7.2718(6) \AA]$ show nonlinear expansion, with nearly all volume change above $150 \mathrm{~K}$. H positions were precisely refined at $8 \mathrm{~K}$. The inner $\mathrm{H} 4$ atom deviates from the idealized $0,0, z$ positions and is disordered over three symmetry-related positions $0.24 \AA$ away from the ternary axis. The outer $\mathrm{H} 3$ atom location is consistent with the previous single-crystal $\mathrm{X}$-ray structure refinement. On the basis of the present thermal expansion data and previous compressibility measurements, the following equation of state for lizardite- $1 T$ is proposed: $V_{P, T}=$ $V_{0}\left[1+32.8 \times 10^{-6}(T-294)-15.5 \times 10^{-4}(P-0.001)\right]$. Accordingly, the constant volume condition requires geothermal gradients on the order of $15^{\circ} \mathrm{C} / \mathrm{km}$.
\end{abstract}

\section{INTRODUCTION}

Because of its simplicity, the structure of lizardite, ideally $\mathrm{Mg}_{3} \mathrm{Si}_{2} \mathrm{O}_{5}(\mathrm{OH})_{4}$, is the archetype model for Mg-rich serpentines (Mellini and Viti 1994). The structure was described with two modules: the 1:1 layer and the interlayer region. The latter involves a sheet of closest-packed octahedral $\mathrm{OH}$ groups, which faces the tetrahedral bases of the adjacent 1:1 layer at a distance that allows hydrogen bonds to be formed. Previous refinements, using X-ray data obtained from seven single crystals, showed that the internal dimensions of the 1:1 layer do not change with chemical substitution or increasing pressure. Instead, the interlayer thickness varied significantly, suggesting that the thickness depends on the hydrogen bonds linking adjacent layers (Mellini 1982; Mellini and Zanazzi 1987, 1989).

The accurate determination of $\mathrm{H}$ positions is difficult with X-ray data. Although a neutron single-crystal data set is optimum, lizardite crystals of sufficient size are unknown. Thus, we conducted a powder neutron diffraction study by full-profile Rietveld refinement, using a polycrystalline sample of almost pure lizardite- $1 T$ from Monte Fico, Elba. This material (Mellini and Viti 1994) occurs in large masses that exhibit excellent crystallinity, as seen from X-ray and electron diffraction. To our knowledge, no other occurrence gives material of similar quality.

\section{EXPERIMENTAL METHODS}

\section{Sample preparation}

The Monte Fico lizardite is compositionally homogeneous (Viti and Mellini, in preparation). Average values
(Mellini and Viti 1994) are as follows: $\mathrm{MgO}=37.97, \mathrm{SiO}_{2}$ $=39.65, \mathrm{Al}_{2} \mathrm{O}_{3}=2.86, \mathrm{FeO}=3.97 \mathrm{wt} \%$.

Lizardite crystals, $0.1-0.5 \mathrm{~mm}$ in diameter, and grains made up of several crystals were selected under the optical microscope. The whole was then gently crushed and analyzed by $\mathrm{X}$-ray powder diffraction to determine the mineralogic purity and crystallinity. Care was taken to avoid chrysotile impurities, which occasionally fill interstices between lizardite crystals, and deformation of lizardite crystals during grinding. The $\mathrm{X}$-ray diffractograms showed only one small extra peak resulting from chrysotile. Lizardite peaks did not indicate stacking faults. For example, the 100 reflection did not show a tail toward higher $2 \theta$ values.

\section{Data collection}

Neutron diffraction data were collected using the multidetector powder diffractometer (TAS3) at the steady-state DR3 reactor at Risø National Laboratory in Denmark. The instrument is a two-axis neutron diffractometer situated at a thermal beam. It has a Debye-Scherrer geometry with a vertical axis and a bank of $20 \mathrm{He}-3$ detectors spanning about $106^{\circ}$ in $2 \theta$ (Als-Nielsen et al. 1988). Each detector covers approximately $5.3^{\circ}$, so step scans of $100 \times 0.053^{\circ}$ give diffraction patterns of 2000 data points. A vertically focusing $\mathrm{Ge}(711)$ monochromator set at $2 \theta=$ $85.1^{\circ}$ provided a beam of incident neutrons with wavelength $1.06966(2) \AA$, as determined from refinement of a diffraction pattern from a standard sample $\left(\alpha-\mathrm{Al}_{2} \mathrm{O}_{3}, R \overline{3} c\right.$, $\left.5.12984 \AA, 55.28333^{\circ}\right)$. The divergence of the incident $(8$ $\mathrm{mm}$ wide $\times 30 \mathrm{~mm}$ high) and diffracted beams was defined to $10 \mathrm{~min}$ by one Soller collimator placed before 
the sample and twenty 10 min Soller collimators placed after the sample in front of each He-3 detector. The resulting instrumental resolution was about $18 \mathrm{~min}$ FWHM at $2 \theta=45^{\circ}$. About $4.7 \mathrm{~g}$ of powdered lizardite sample were introduced in a sealed cylindrical vanadium container $(9 \mathrm{~mm}$ inner diameter $\times 40 \mathrm{~mm}$ height and 0.1 $\mathrm{mm}$ wall thickness). Before sealing, the vanadium container was evacuated and filled with $\mathrm{He}$ exchange gas $(\sim 300$ mbar) to ensure thermalization of the powder grains.

For diffraction experiments at room temperature (294 $\mathrm{K})$, the vanadium container was placed directly on the diffractometer sample table, where a special device provided for sample rotation around the $\omega$ axis of the diffractometer during data collection. The low-temperature diffraction patterns at $8(1)$ and $150(1) \mathrm{K}$ were obtained using a Displex cooling device with a cylindrical aluminum vacuum jacket with an overall wall thickness of 2 $\mathrm{mm}$ in the diffraction plane. This device was fixed onto the diffractometer sample table, and no sample rotation was provided. The vanadium container was screwed directly onto the low-temperature copper block of the cooling device. This copper block can be heated above base temperature (approximately $8 \mathrm{~K}$ ) and is also in direct contact with a calibrated germanium thermometer and a $100 \Omega$ platinum resistance thermometer. The germanium thermometer was used for measuring temperatures up to $80 \mathrm{~K}$, and the platinum resistor for measuring temperatures from 50 to $300 \mathrm{~K}$. Temperatures were monitored at $10 \mathrm{~ms}$ intervals and recorded simultaneously with the step-scan data.

The data collection was, in all cases, divided into several experiments, each defined by its monitor count measured in the primary beam between entrance collimator and sample. Monitor counts on the order of $10^{4}-10^{5}$ were used, corresponding to about $1-10 \mathrm{~h}$. Thus, difference patterns between successive experiments could be calculated to check for structural changes during the measurement, as might be expected for the low-temperature experiments if the sample were not in complete thermal equilibrium. For the latter experiments, the raw observed intensities were corrected by subtracting the contribution of the empty cryostat. Because these corrections were small in comparison with the resulting intensities, no additional treatment of errors was made, and estimated standard deviations obtained from counting statistics were used throughout. The background level and fluctuations of these patterns were, within 1.9-2.5 times the estimated standard deviation from counting statistics, the same as those obtained at room temperature. No visible effect of graininess, which might arise from the lack of sample rotation in the cryostat, was observed.

The last detector had a greater noise fluctuation in all experiments, and an intensity drift was occasionally observed for the first detector. After the early stages of refinement, these data were therefore excluded from least-squares calculations. Other regions were eventually excluded to eliminate impurity peaks as noted below.
In Figure 1, the observed neutron powder diffraction patterns at 8,150 , and $294 \mathrm{~K}$ are shown. Note that the peak definition is greatly improved in low-temperature experiments, particularly in the high- $2 \theta$ region.

\section{Structure refinement}

The GSAS program system (Larson and Von Dreele 1994) was used for Rietveld refinement. The space group $P 31 \mathrm{~m}$ and atomic parameters were taken from singlecrystal X-ray diffraction results (Mellini and Viti 1994) for the same specimen used in the present study. The octahedral site occupancy (hereafter referred to as " $\mathrm{Mg}$ site" to be consistent with previous papers) was set at $0.947 \mathrm{Mg}+0.053 \mathrm{Fe}$ to correspond to the chemical analysis (average of $\sim 50$ crystals). A check for the constancy of these values during the final stages of refinement showed only negligible changes, confirming the microprobe results. No account was made for the low Al content (see above), considering that the neutron-scattering length of $\mathrm{Al}(3.45 \mathrm{fm})$ is close to that of the elements for which it might substitute, i.e., Si $(4.15 \mathrm{fm})$ and $\mathrm{Mg}(5.38 \mathrm{fm})$.

During the first stage of Rietveld refinement, all parameters were fixed, except for the scale factor, background coefficients (a three-term cosine Fourier series), and unitcell parameters. The instrument zero point was fixed at $0.034^{\circ}(2 \theta)$, as determined by the standard $\alpha-\mathrm{Al}_{2} \mathrm{O}_{3}$ refinement. Subsequently, the peak shape was refined using a pseudo-Voigt profile function, which contained the Gaussian $U, V, W$ parameters (Caglioti et al. 1958), a Lorentzian $\gamma=X /(\cos \theta)$ parameter to account for particle size, and a cut-off of the wings at $0.1 \%$ of the peak maximum. The $U, V$, and $W$ Gaussian parameters were fixed at values obtained from the standard $\alpha-\mathrm{Al}_{2} \mathrm{O}_{3}$ refinement, and only the particle-size parameter was refined. The Lorentzian $X$ values obtained from the three patterns ranged from $11.4(8 \mathrm{~K})$ to 12.2 (294 K). A MarchDollase preferred-orientation correction (Dollase 1986) was introduced, with [001] as the preferred direction, and the corresponding parameter converged to the same value of $1.17(1)$ for all refinements.

Special care was taken in background modeling to avoid effects from small chrysotile impurities. A tiny quantity of chrysotile impurity was isolated and mounted in a Debye-Scherrer camera equipped with CHI-70, a Gandolfi device (Gregorkiewitz 1994; Serrano-Santos and Gregorkiewitz 1995). The resulting film was converted to a digitized diffraction pattern with intensity vs. scattering angle (Nguyen and Jeanloz 1993). Its comparison with the observed and calculated X-ray patterns of lizardite indicated that a small amount of chrysotile might account for many discrepancies, such as a few weak extra peaks, shoulders, and an anomalous broadening at the base of some lizardite peaks. Because chrysotile exhibits much lower crystallinity, the discrepancies appear as broad, nonrandom fluctuations of the background and could easily be recognized also in the neutron patterns of our lizardite sample. Seven chrysotile contributions were then removed from the observed neutron patterns by subtrac- 


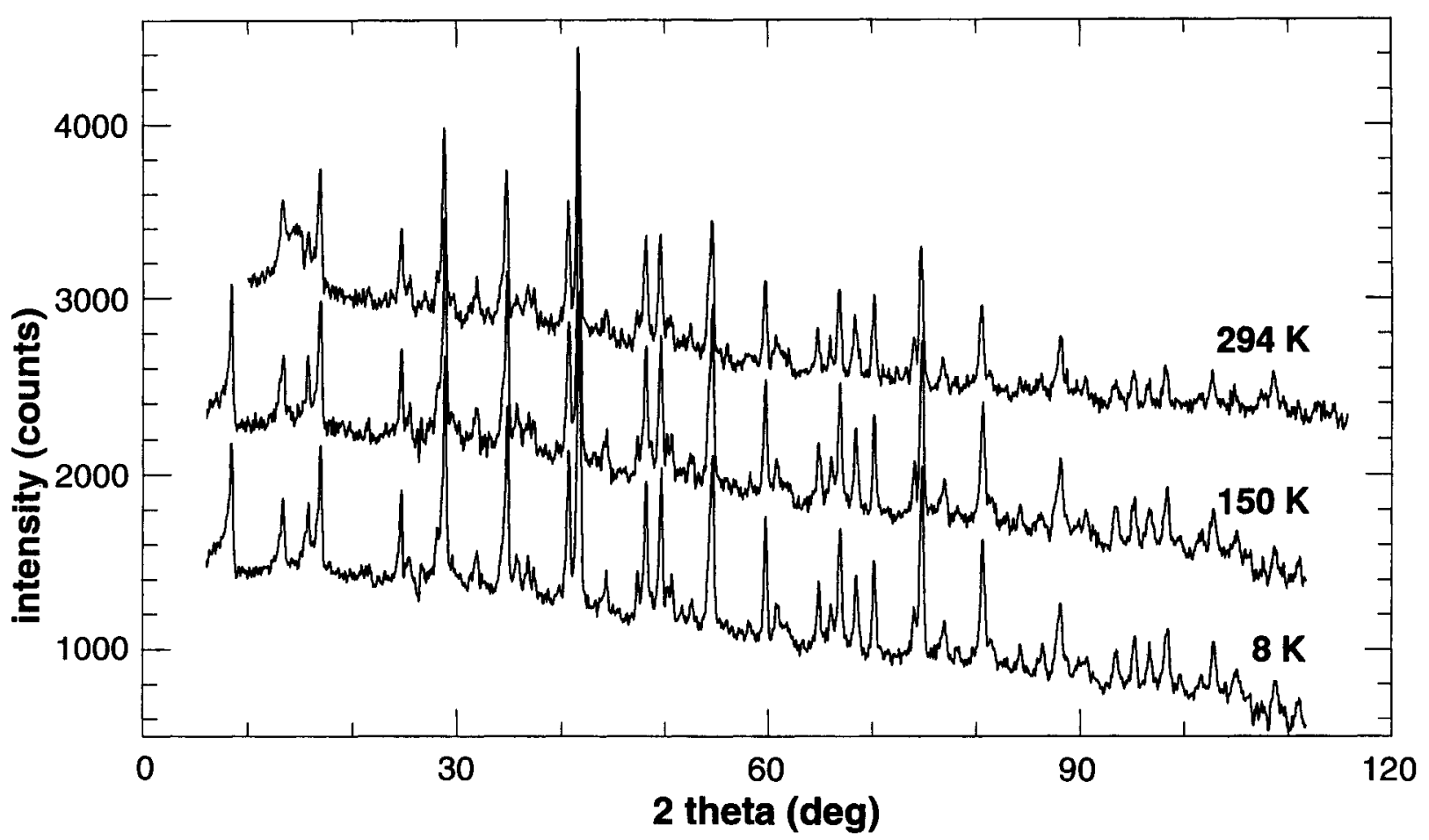

Figure 1. Observed neutron powder diffraction patterns for lizardite- $1 T$ at 8,150 , and $294 \mathrm{~K}$. The 150 and $294 \mathrm{~K}$ patterns are displaced for comparison.

tion as fixed background points. After such corrections, the refinement converged to $\chi^{2}$ values of $1.57,1.37$, and 1.06 and $R_{\text {Вragg }}$ values of $0.19,0.17$, and 0.27 , respectively, for the 8,150 , and $294 \mathrm{~K}$ refinements.

At this stage, atomic parameters were allowed to refine. Isotropic displacement factors were refined for four groups of atoms, namely Si-Mg-Fe, O1-O3-O4, H3-H4, and O2. To improve convergence, 35 soft constraints, corresponding to the $\mathrm{Si}-\mathrm{O}, \mathrm{Mg}-\mathrm{O}, \mathrm{O}-\mathrm{O}, \mathrm{Si}-\mathrm{Si}$, and $\mathrm{O}-\mathrm{H}$ distances, were imposed. The ideal values for these parameters were taken from lizardite single-crystal X-ray data (Mellini and Viti 1994), except for the O-H distance, which was set to $0.97(5) \AA$ (Chiari and Ferraris 1982). The weight of the soft constraints was progressively reduced during successive refinement cycles. Atomic coordinates were refined, beginning with $\mathrm{Si}, \mathrm{Mg}$, and $\mathrm{Ol}$, $\mathrm{O} 3, \mathrm{O} 4$ and followed by the $\mathrm{H}$ atoms and $\mathrm{O} 2$.

Least-squares refinements using 8,150 , and $294 \mathrm{~K}$ data converged to $\chi^{2}$ values of $1.35,1.10$, and 0.61 and to $R_{\text {Bragg }}$ values of $0.12,0.14$, and 0.14 , respectively (Table 1). In Figure 2, the observed and calculated patterns, corresponding to the Rietveld refinement using $8 \mathrm{~K}$ data, are given along with the difference curve.

\section{Results}

\section{Unit-cell parameters}

Unit-cell parameters are shown in Table 1. The roomtemperature cell $[a=5.3332(2), c=7.2718(6) \AA]$ matches values obtained by $\mathrm{X}$-ray diffraction of two selected crys- tals $[a=5.330(4)$ and 5.338(4), $c=7.257(6)$ and 7.269(6) $\AA ;$ Mellini and Viti 1994]; the current values represent the average of about $10^{7}$ single crystals. The unit-cell parameters decrease upon cooling, with the $c$ parameter being more sensitive to temperature than the $a$ parameter (Fig. 3). Maximum variation occurs between 150 and 294 $\mathrm{K}$, and a nonlinear dependence of the $a$ and $c$ unit-cell parameters of lizardite with respect to temperature is evident. These results emphasize the need for caution in assumptions regarding extrapolations of unit-cell parameters, especially for thermodynamic calculations. The value calculated between 150 and $294 \mathrm{~K}$ is accepted as a lower estimate of the expansion coefficient of lizardite. Nonlinear behavior was noted by Mellini and Zanazzi (1989) in their determination of lizardite compressibility.

TABLE 1. Rietveld refinement parameters and unit-cell data of lizardite-1 $T$ at 8,150 , and $294 \mathrm{~K}$

\begin{tabular}{lccc}
\hline \hline$T(\mathrm{~K})$ & 8 & 150 & 294 \\
\hline$R_{\mathrm{p}}$ & 0.027 & 0.028 & 0.024 \\
$R_{\mathrm{wp}}$ & 0.035 & 0.036 & 0.031 \\
$R\left(F^{2}\right)$ & 0.124 & 0.137 & 0.143 \\
No. obs & 274 & 271 & 250 \\
No. p & 24 & 23 & 23 \\
$\chi^{2}$ & 1.349 & 1.103 & 0.612 \\
$a(\AA)$ & $5.3267(2)$ & $5.3260(2)$ & $5.3332(2)$ \\
$c(\AA)$ & $7.2539(6)$ & $7.2574(6)$ & $7.2718(6)$ \\
$V\left(\AA^{3}\right)$ & $178.25(1)$ & $178.28(1)$ & $179.12(1)$ \\
\hline
\end{tabular}

Note: $R_{p}=$ profile residual, $R_{w p}=$ weighted profile residual, $R\left(F^{2}\right)=$ $R_{\mathrm{Bragg}}$, No. obs $=$ number of reflections $F^{2}(h k /)$ extracted, No. $\mathrm{p}=$ number of variables. 


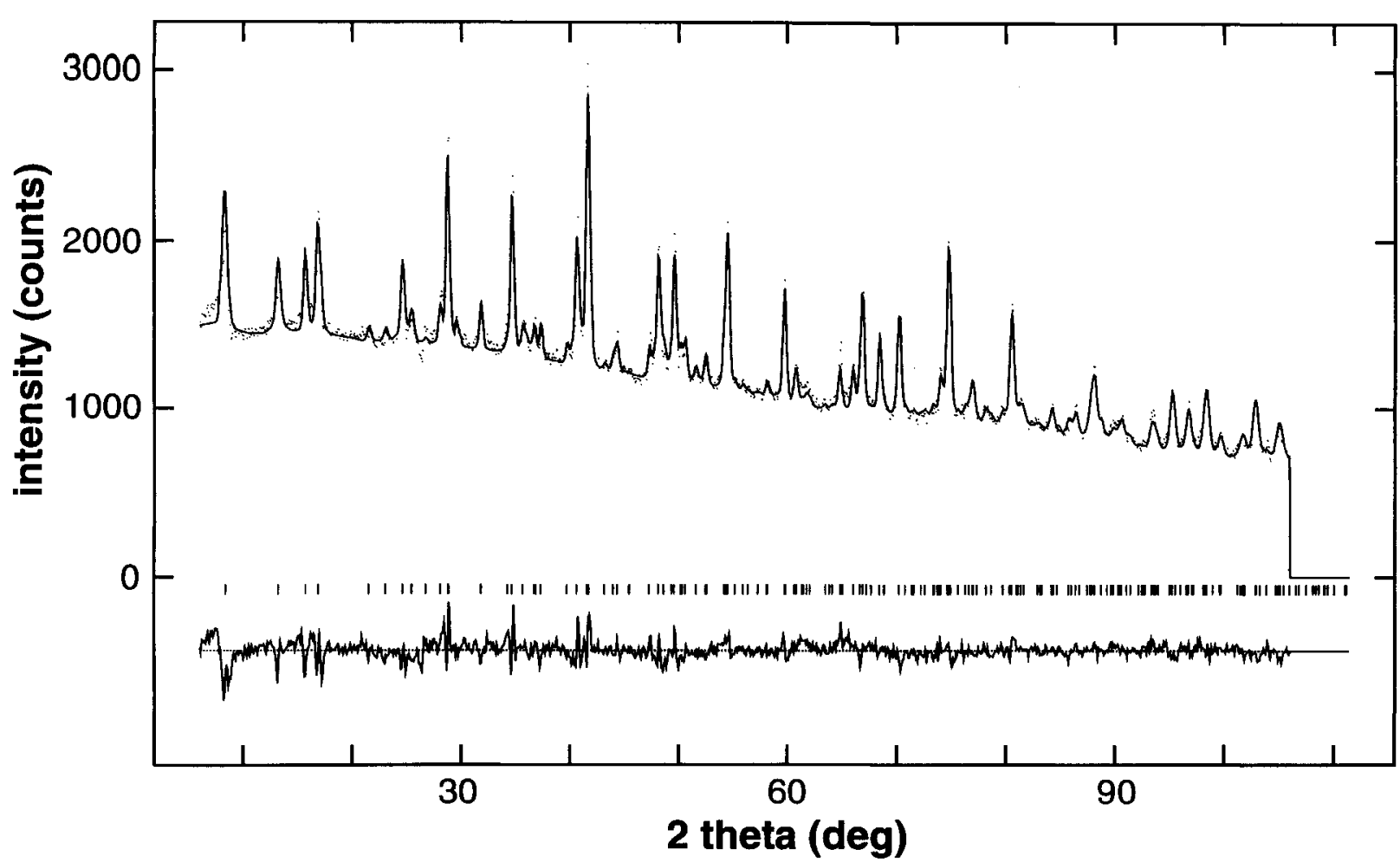

Figure 2. Observed (points), calculated (solid line), and difference pattern corresponding to the Rietveld refinement using the $8 \mathrm{~K}$ data. Tick marks indicate positions of allowed Bragg reflections.

\section{Structural results}

The Rietveld refinement based on powder neutron diffraction closely matches the results from single-crystal $\mathrm{X}$-ray diffraction (Table 2, cf. Table 2 in Mellini and Viti

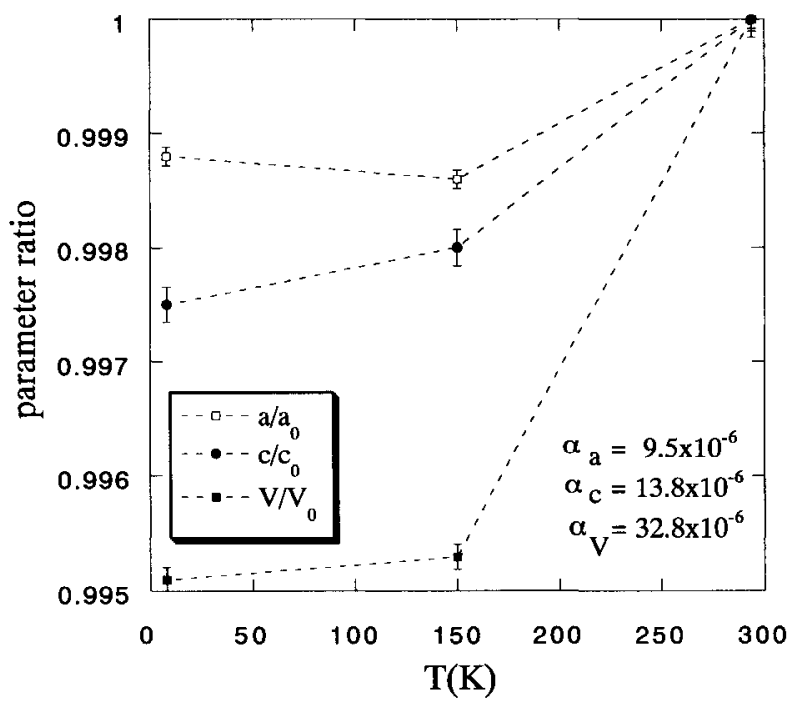

FiguRE 3. Normalized temperature dependence of the unitcell parameters of lizardite-1T. The $\alpha$ values are the expansion coefficients measured between 150 and $294 \mathrm{~K}$. Error bars correspond to \pm 1 estimated standard deviation.
1994). Only the atomic coordinates obtained from the 8 $\mathrm{K}$ refinement are reported here because they represent the most significant structural result. As in the previous study, negative ditrigonalization characterizes the $1 T$ polytype, as predicted by Mellini (1982). The deviation from hexagonal configuration is $\alpha=-2.6^{\circ}$, which compares to the -2.7 and $-2.6^{\circ}$ obtained by $\mathrm{X}$-ray analysis at room temperature.

\section{H positions}

Two $\mathrm{H}$ sites (Fig. 4) occur in lizardite. H3 is the outer $\mathrm{H}$ atom, which is bonded to $\mathrm{O} 3$ and links the octahedral

TABLE 2. Atomic positions and isotropic mean-square displacements $\left(U_{\text {lso }}\right)$ of lizardite- $1 T$ obtained from Rietveld refinement of the $8 \mathrm{~K}$ pattern

\begin{tabular}{lllcccc}
\hline \hline & \multicolumn{1}{c}{$x$} & & \multicolumn{1}{c}{$\boldsymbol{c}$} & $\begin{array}{c}U_{\text {iso }} \\
(8 \mathrm{~K})\end{array}$ & $\begin{array}{c}U_{\text {iso }} \\
(150 \mathrm{~K})\end{array}$ & $\begin{array}{c}U_{\text {ibo }} \\
(294 \mathrm{~K})\end{array}$ \\
\hline $\mathrm{Si}$ & $1 / 3$ & $2 / 3$ & $0.070(1)$ & $20(8)$ & $33(9)$ & $42(8)$ \\
$\mathrm{Mg}$ & $0.324(2)$ & 0 & $0.447(2)$ & $20(8)$ & $33(9)$ & $42(8)$ \\
$\mathrm{O} 1$ & $1 / 3$ & $2 / 3$ & $0.292^{*}$ & $2(5)$ & $5(5)$ & $71(7)$ \\
$\mathrm{O} 2$ & $0.507(2)$ & 0 & $-0.014(2)$ & $88(12)$ & $112(13)$ & $157(13)$ \\
$\mathrm{O} 3$ & $0.665(2)$ & 0 & $0.587(1)$ & $2(5)$ & $5(5)$ & $71(7)$ \\
$\mathrm{O} 4$ & 0 & 0 & $0.291(3)$ & $2(5)$ & $5(5)$ & $71(7)$ \\
$\mathrm{H} 3$ & $0.646(3)$ & 0 & $0.715(2)$ & $78(23)$ & $157(19)$ & $321(22)$ \\
$\mathrm{H} 4$ & $0.046(6)$ & $0.046(6)$ & $0.172(4)$ & $78(23)$ & $157(19)$ & $321(22)$ \\
\hline
\end{tabular}

Note: The displacement parameters corresponding to the 150 and 294 $K$ refinements are reported for comparisons. $U_{i s o}$ reported as squared picometers.

* Not refined in order to fix unit-cell origin. 


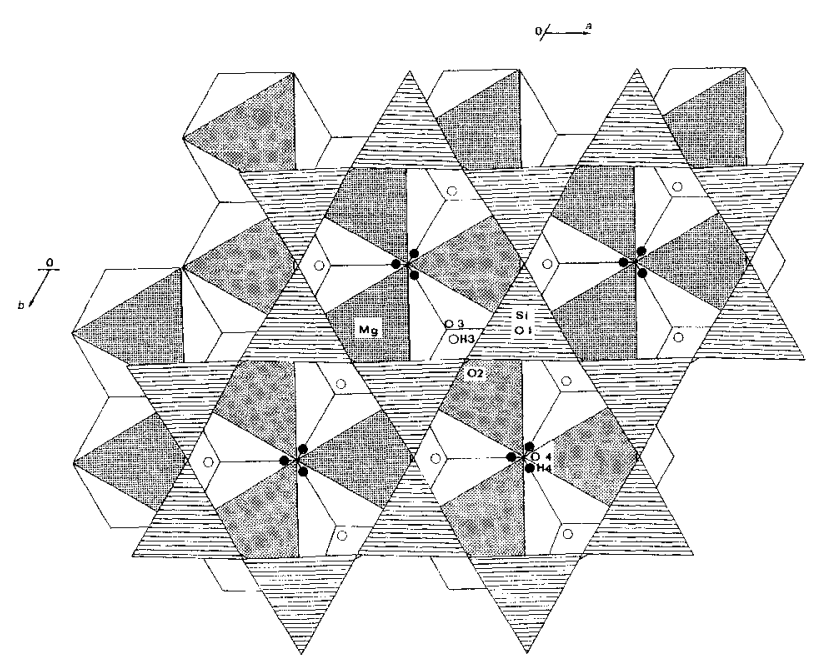

Figure 4. Projection of the crystal structure of lizardite- $1 T$ from the $8 \mathrm{~K}$ refinement. Open circles $=\mathrm{H} 3=$ outer $\mathrm{H}$ atom, solid circles $=\mathrm{H} 4=$ inner $\mathrm{H}$ atom. Note that the structure is viewed from the bottom with $c$ pointing away from the observer.

sheet of a given 1:1 layer to the tetrahedral sheet of the adjacent 1:1 layer. $\mathrm{H} 4$ is the inner $\mathrm{H}$ atom, bonded to $\mathrm{O} 4$, and ideally located on the ternary rotation axis perpendicular to the ditrigonal ring with coordinates $0,0, z$.

H3 was located, although with greater accuracy, near the position obtained by the previous $\mathrm{X}$-ray determination $(0.646,0,0.715$ vs. $0.660,0,0.710)$. The important point is that this study confirms previous conclusions. In particular, from Figure 4, we note a correlated atomic displacement. In projection, $\mathrm{H} 3$ is slightly displaced from its idealized position on the perpendicular over $\mathrm{O} 3$ and toward $\mathrm{O} 2$. In concert with this, the $\mathrm{O} 2$ atom in the adjacent 1:1 layer is displaced toward $\mathrm{H} 3$, giving a slightly ditrigonal distortion of the six-membered ring of silicate tetrahedra. Thus, the interlayer hydrogen bond strengthens to give an $\mathrm{O} 2-\mathrm{H} 3$ distance of $2.10 \AA$.

For $\mathrm{H} 4$, a short $\mathrm{O}-\mathrm{H}$ distance $(\mathrm{O} 4-\mathrm{H} 4 \approx 0.8 \AA)$ suggests that the $0,0, z$ coordinate is an average position, with H4 disordered over three or six symmetry-related positions off the ternary axis. Among various alternatives tested in the last stages of the $8 \mathrm{~K}$ refinement, two cases are considered here. In the first case, $\mathrm{H} 4$ is displaced along [100], with subsequent decrease of the $\mathrm{H} 4-\mathrm{O} 4-\mathrm{Mg}$ angle, whereas in the second case $\mathrm{H} 4$ is displaced along [110], with subsequent increase of the H4-O4-Mg angle. The latter refinement, corresponding to $\mathrm{H} 4$ at 0.046 , $0.046,0.172$ (i.e., at $0.24 \AA$ off the ternary axis), gave the best agreement with observed data according to the test by Hamilton (1965). This result is explained as a combined effect of tetrahedral ring ditrigonalization and octahedral substitution. In particular, $\mathrm{H} 4$, in the observed off-axis position, points toward one of the three $\mathrm{O} 2$ atoms that, because of the ditrigonalization of the ideally hexagonal six-membered tetrahedral ring, moved toward the center of the ring (Fig. 4). Thus, the displacement short-

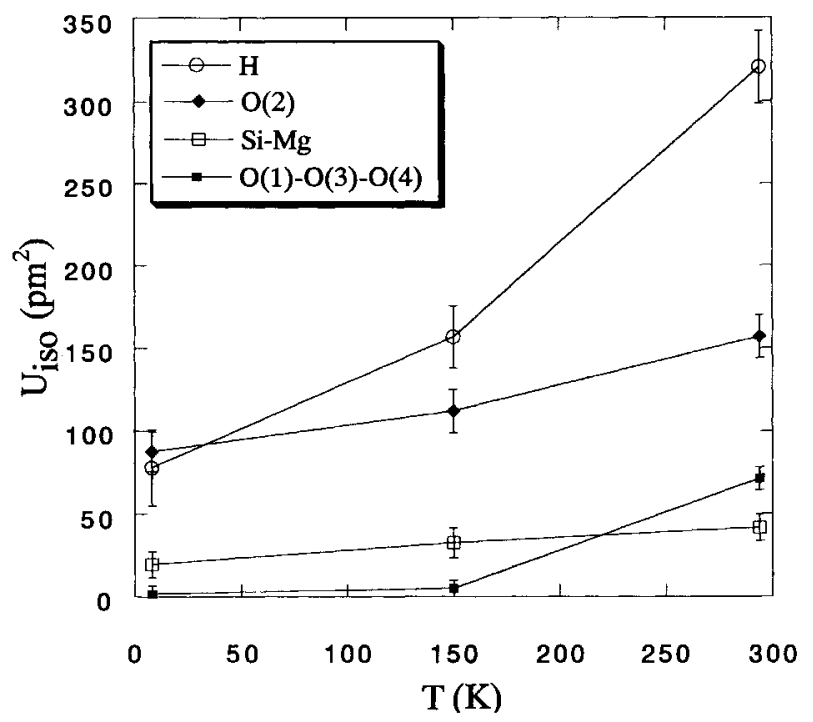

Figure 5. Temperature dependence of the isotropic DebyeWaller factor in lizardite-1 $T$. Error bars correspond to \pm 1 estimated standard deviation.

ens some $\mathrm{O} 2-\mathrm{H} 4$ distances. Moreover, the observed increase of the $\mathrm{H} 4-\mathrm{O} 4-\mathrm{Mg}$ angles is expected for the substitution of $\mathrm{Mg}$ with ions of higher charge, as seen in dioctahedral micas or trioctahedral micas with different elements in the octahedral positions (see, e.g., Serratosa and Bradley 1958; Giese 1979).

\section{Debye-Waller parameters}

Mellini and Viti (1994) observed anomalously large Debye-Waller factors for $\mathrm{O} 2$, in particular for the $U_{11}$ component. They tentatively attributed this anomaly to static or dynamic positional disorder arising from negative-to-positive ditrigonalization of the six-membered rings in the tetrahedral sheets. In Rietveld powder diffraction refinements, it is difficult to obtain meaningful anisotropic Debye-Waller parameters, and it is known that, even in the isotropic case $\left(U_{\text {iso }}\right)$, values may greatly differ from those obtained by single-crystal diffraction of the same material. The present result can, however, be used for comparison of the data obtained at different temperatures. In fact, Figure 5 shows a general decrease of Debye-Waller factors with temperature, which is almost already complete at $150 \mathrm{~K}$. However, whereas meansquare displacement amplitudes of all other $O$ atoms approach zero, $\mathrm{O} 2$ (as well as the $\mathrm{H}$ atoms) maintains values well above zero. This means that, for those atoms, the Debye-Waller factors cannot entirely be explained by thermal motion, in support of the above-mentioned idea of positional disorder, which might result from occasional positive ditrigonalization of the tetrahedral sheet.

\section{Discussion AND CONCLUSION}

We derive an approximate equation of state of lizardite, using the present thermal-expansion data (but great- 
er expansion coefficients are expected if measured at higher temperatures) for the Elba lizardite, together with compressibility coefficients calculated from the data reported for the near-isochemical Coli lizardite (Mellini and Zanazzi 1989). The approximate relations are as follows:

$$
\begin{aligned}
a_{P, T}= & a_{0}\left[1+9.5 \times 10^{-6}(T-294)\right. \\
& \left.-2.2 \times 10^{-4}(P-0.001)\right] \\
c_{P, T}= & c_{0}\left[1+13.8 \times 10^{-6}(T-294)\right. \\
& \left.-11.2 \times 10^{-4}(P-0.001)\right] \\
V_{P, T}= & V_{0}\left[1+32.8 \times 10^{-6}(T-294)\right. \\
& \left.-15.5 \times 10^{-4}(P-0.001)\right] .
\end{aligned}
$$

Clearly $P$ (here given in kilobars) and $T$ are not analogous in lizardite. Although linear expansion along [100] is roughly similar to that along [001], the compressibility along [001] is considerably larger than that along [100]. Balancing effects of $P$ and $T$ may be estimated by considering volume expansion and compressibility coefficients. From the above equations, we find that a $50^{\circ} \mathrm{C}$ increase is offset by a $1 \mathrm{kbar}$ increase. Assuming 3 is a reliable specific gravity for serpentinites, the $1 \mathrm{kbar}$ increase relates to a depth of $3.3 \mathrm{~km}$. Therefore, no important volume change would occur for serpentinites emplaced under a geothermal gradient of $15^{\circ} \mathrm{C} / \mathrm{km}$. Of course, if the gradient is higher, a volume increase would occur; conversely, if the gradient is lower, contraction would occur.

\section{ACKNOWLEDGMENTS}

Neutron-scattering experiments were performed at the DR3 reactor at Risø National Laboratory and financially supported by the EC Large Installation Plan. The manuscript was greatly improved through the constructive criticism of the two referees, D.L. Bish and S. Guggenheim.

\section{REFERENCES CITED}

Als-Nielsen, I., Andersen, N.H., Broholm, C., Clausen, K.N., and Lebech, B. (1988) The multi-detector powder neutron diffractometer at Rise National Laboratory. Rise National Laboratory, DK-4000 Roskilde, Risø-M-2720, 6.

Caglioti, G., Paoletti, A., and Ricci, F.P. (1958) Choice of collimators for a crystal spectrometer from neutron diffraction. Nuclear Instruments Methods, 3, 223-228.

Chiari, G., and Ferraris, G. (1982) The water molecule in crystalline hydrates studied by neutron diffraction. Acta Crystallographica, B38, 23312341.

Dollase, W.A. (1986) Correction of intensities for preferred orientation in powder diffractometry: Application of the March model. Journal of Applied Crystallography, 19, 267-272.

Giese, R.F., Jr. (1979) Hydroxyl orientation in 2:1 phyllosilicates. Clays and Clay Minerals, 27, 213-223.

Gregorkiewitz, M. (1994) Geometrical limits and improvement of the diffraction optics in Gandolfi cameras. Journal of Applied Crystallography, 27, 855-859.

Hamilton, W.C. (1965) Significance tests on the crystallographic $R$ factor. Acta Crystallographica, 18, 502-510

Larson, A.C., and Von Dreele, R.B. (1994) GSAS General Structure Analysis System. Los Alamos National Laboratory, LAUR 86-748.

Mellini, M. (1982) The crystal structure of lizardite $1 T$ : Hydrogen bonds and polytypism. American Mineralogist, 67, 587-598.

Mellini, M., and Zanazzi, P.F. (1987) Crystal structure of lizardite- $1 T$ and lizardite-2H1 from Coli, Italy. American Mineralogist, 72, 943-948.

(1989) Effects of pressure on the structure of lizardite-1 $T$. European Journal of Mineralogy, 1, 13-19.

Mellini, M., and Viti, C. (1994) Crystal structure of lizardite-1T from Elba, Italy. American Mineralogist, 79, 1194-1198.

Nguyen, H., and Jeanloz, R. (1993) A computer program to analyze X-ray diffraction films. Review of Scientific Instruments, 64, 3456-3461.

Serrano-Santos, B., and Gregorkiewitz, M. (1995) Identificación de sólidos cristalinos a escala microscópica: Nuevas posibilidades para la difracción de polvo. Química e Industria (Madrid), 42, 421-426.

Serratosa, J.M., and Bradley, W.F. (1958) Determination of the orientation of $\mathrm{OH}$ bond axis in layer silicates by infrared absorption. Journal of Physics and Chemistry, 62, 1164-1167.

Manuscript ReCeived August 2, 1995

MANUSCRIPT ACCEPTED APRIL 24, 1996 